\section{Lessons from a Greek roadmap}

\author{
Stephen Hancocks OBE \\ Editor-in-Chief
}

Send your comments to the

Editor-in-Chief,

British Dental Journal

64 Wimpole Street,

London

W1G 8YS

Email bdj@bda.org
On a recent holiday to a Greek island (yes, even an editor-inchief is occasionally allowed a few days off between issues) I learnt several rather valuable lessons, each of which was in one way or another the result of reflection; one of the functions that time out should allow.

The first was connected with the roadmap. We bought it as soon as we arrived in anticipation of having a hire care delivered to the hotel the next morning and wanting to plan some visits. It was a smart, laminated map which the sales blurb introduced as being flexible in that the user could draw out routes using a felt-tipped pen and then wipe them off afterwards, a property that had somewhat questionable value, as we shall see. For those not familiar with the quality of roads on Greek islands I should explain that they might be politely described as variable. Some are very good, some not so good, some peter out rather unexpectedly into little more than goat tracks while others stop abruptly, apparently in the middle of nowhere for no discernable reason other than that they do.

We set off for a sandy beach located on the south of the island. Out of the immediate environs of the hotel, a clutch of tavernas and the usual ungainly cluster of seaside shops selling gee-gaws and faded postcards (does anyone send postcards anymore?) the road turned inland and began weaving its way around hills and up and down hairpins skirting the majestic mountains. As navigator, I became increasingly aware of a number of handicaps. Not all junctions, often slightly ill defined on the road themselves anyway, were marked; some villages seemed to have been missed from the plan completely; the villages that were identified were usually done so with names spelt significantly differently to the sign as we approached them (and often in Greek only, which is not my strongest suit) and finally, the hairpins were represented not with the accuracy of a cartographer but with the gracious and meandering appropriateness of an artist in love with the romance of a beautiful island rather than the necessity of getting anywhere quickly. By now, the lamination of the map had also come into its own as being wipe-clean for sweat. Excuse me.

\section{BEING AWARE OF THE BIGGER PICTURE}

The answer was to be guided more by the compass than the map and the lesson was to look not at the number of twists on the tarmac but the direction of the road ahead; in short, to be aware of the bigger picture. As dentists I think we are so often, as I was, far too busy examining the minutiae that we lose sense of direction of the whole. This is also as a result of the confusion, or perhaps conflict, between clinical judgement and business sense; the comparison of the twists and turns of a root canal versus the strategic direction of a piece of legislation. We might naturally be consumed by the very specific detail of how the newly launched NHS pilot schemes are constituted but are we deflected from the fact that ultimately they will have the same 'third-party payer' characteristics of every other similar contract anywhere else? Deciding to specialise in one clinical discipline might seem like the opportunity to devote a working life to a passion, but are there sufficient patients to fulfil the need of the appointment book? You will find your own examples.

Having eventually reached the Greek beach, had a pleasant day and returned, further time for reflection came in the hotel dining room. There was only one British couple there to our certain knowledge, the other guests being mainly Italian, Greek, German and some from Eastern European countries. Dressed for leisure and without the usual cultural references as guidance it struck me how very much more difficult it is to assess people without such clues and familiar landmarks, another form of roadmap I suppose. In our professional lives we are remarkably adept and usually very precise in our summation of a new patient in the few seconds that it takes them to enter the surgery and walk to the dental chair. But are we as discerning when it comes to business arrangements? Again, while we take the procedures of clinical assessment and decision making with painstaking attention to detail, are we also in danger of missing some of the wider issues entangled with the people with whom we do business? Our patients rightly trust us, but to what extent can we honestly report that we trust all those with whom deal?

Well, musings from a break from routine but a final one which may or may not be of greater significance still. While driving round the island the other observation was of many skilfully constructed dry stones walls running for miles along carefully contoured terraces which once enclosed olive groves and other agricultural enterprise but are now long abandoned. With the Greek debt crisis might they one day soon be reembraced and is there a lesson there for us as well? A roadmap too far perhaps, but the holiday was good.

DOI: $10.1038 /$ sj.bdj.2011.678 